\title{
CAPTURING PROTOTYPE PROGRESS IN DIGITAL FABRICATION EDUCATION
}

\author{
Barhoush, Yazan A M (1); Erichsen, Jørgen Falck (2); Sjöman, Heikki (2); Georgiev, Georgi V. \\ (1); Steinert, Martin (2) \\ 1: University of Oulu; 2: Norwegian University of Science and Technology (NTNU), Norway
}

\begin{abstract}
The early (pre-requirement) stages of product development can provide relevant insights into the creative design process. At these stages, the communication of ideas during the prototyping process can serve as a rich source for information. In this paper, we attempt to document physical prototypes generated during the design process. We describe the design and preliminary testing of Protobooth Oulu: a system that can be used for documenting the process of prototyping products through capturing process output 'snapshots' in time at the early stages of product development. Our primary motivation is to facilitate documentation and reflection from an educational perspective. We tested the system during a course on digital fabrication in a FabLab environment, where ten teams documented their coursework over the course of six weeks. Managing to capture prototypes over time, analysis of the captured data showed evolution and major changes in the prototypes. Such data can be used for understanding the process of prototyping and consequently provide means to improve prototype and overall creative performance. We outline a future Protobooth system in terms of functionality.
\end{abstract}

Keywords: Design education, Design process, Creativity, Prototyping, Digital fabrication

\section{Contact:}

Barhoush, Yazan A M

University of Oulu

Center for Ubiquitous Computing

Finland

yazan.barhoush@oulu.fi

Cite this article: Barhoush, Y.A.M., Erichsen, J.F., Sjöman, H., Georgiev, G.V., Steinert, M. (2019) 'Capturing Prototype Progress in Digital Fabrication Education', in Proceedings of the 22nd International Conference on Engineering Design (ICED19), Delft, The Netherlands, 5-8 August 2019. DOI:10.1017/dsi.2019.50 


\section{INTRODUCTION}

Prototyping and iterative testing are effective approaches when dealing with engineering design problems. Human-centric creative design approaches are employed for rapid conceptual prototyping (Leifer and Steinert, 2011). Both approaches are needed for tackling issues in User-Centered Design (UCD) (Pierce et al., 2015; Wolf et al., 2006).

Some studies in creativity and design attempted to identify aspects of creativity in design and confirm the validity of models of creative design, e.g. the co-evolution model (Dorst and Cross, 2001). Others such as (Swan et al., 2010) introduced the processional character in design and showed how it can be used in identifying the 'unfolding, contingent nature of particular kinds of activity'. The design activity of a processional character progresses incrementally; it is a continuous process where past steps shape future steps. Therefore, owing to such nature of design, and as can be seen in Sjöman et al. (2017), UCD needs interactive applications that can be evaluated with end users, where circular design is employed by designers to create new creative applications and materials.

In this paper, we attempt to document physical artefacts (i.e. prototypes) not only with ideas generated in the design process but also with snapshots throughout the prototyping process in order to help devise future aids and interventions in terms of design education. We use a system, Protobooth Oulu, with a main motivation to facilitate documentation from an educational perspective. The primary goal of such a system is to make designers reflect on their concepts (by reviewing their prototypes). A further and overarching goal is not only to produce documentation that can be used by practitioners and designers, but can also be used in research.

Figure 1 illustrates the authors' attempt to provide a taxonomy for documenting physical artefacts. The reasons for documentation and reflection are of particular interest in our case. Our focus is on engineering projects where creativity is 'allowed'; hence, before the requirements are fixed, as in fuzzy front-end practices seen in Herstatt et al. (2006). Digital fabrication is one such field where creativity is encouraged.

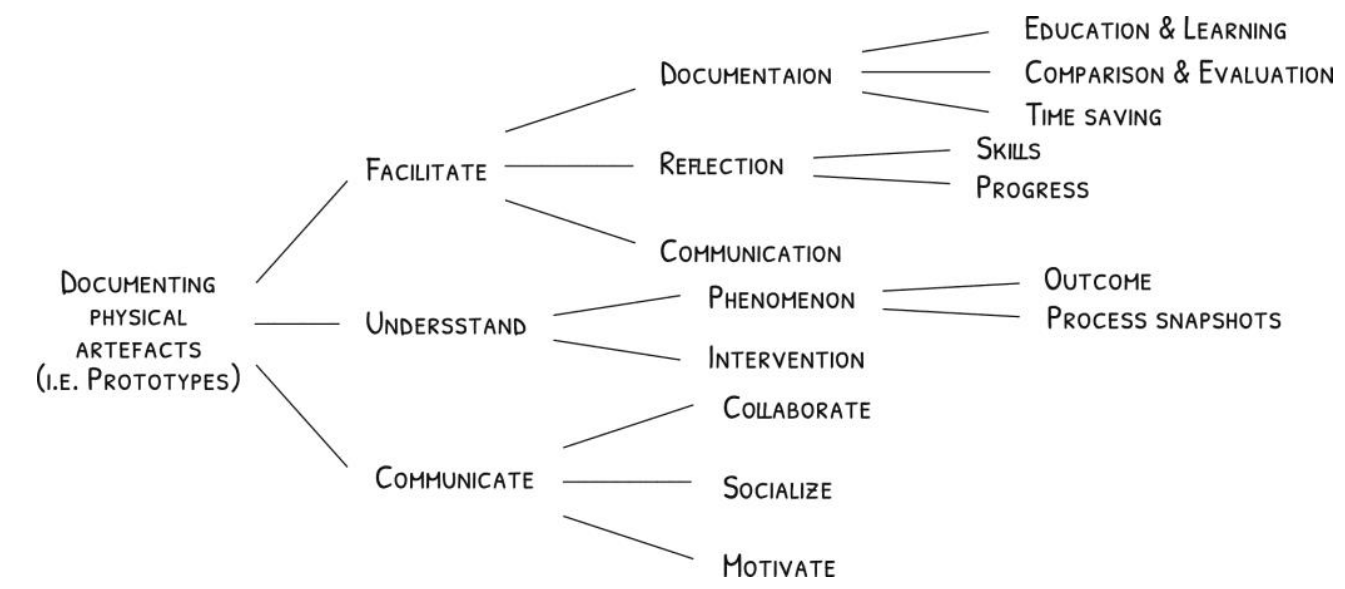

Figure 1. Possible taxonomy of reasons to document physical artefacts (i.e. prototypes) in design

\section{DOCUMENTING PHYSICAL ARTEFACTS AND PROTOTYPES IN DESIGN}

The communication of ideas during the development of artefacts serves as a rich source for information. This can be seen in Perry and Sanderson (1998), which highlighted the role of communication and artefacts in design work. The researchers supplied empirical observations to show design work as a joint and coordinated learning process that evolves in a nonlinear process which employs 'artefacts to support mediate and organize communication'. Documentation practices can also be essential for design and UCD approaches. Zimmerman et al. (2010) showed how difficult it can be to evaluate research findings unless there is a thorough structured documentation of the design processes. Additionally, Dalsgaard and Halskov (2012) discussed reflective design documentation, where they designed a system to capture data from the design process for use in design research. Their system showed how artefacts evolve during the design phase, which can help understand the design processes themselves. 


\subsection{WorkspaceNavigator system}

The problem of documenting information during the various prototyping phases has been addressed by researchers in many forms and environments. A favourite topic for research has been meeting capture, its infrastructure, and the interfaces needed for presenting materials for meetings. Ju et al. (2004) described WorkspaceNavigator, focusing on retrieval and access methods in technology-rich environments, to 'assist in recall and reuse of material generated during informal meetings', such as interactive workspaces. The researchers argued that WorkspaceNavigator grants a 'coherent, unified interface for post-facto retrieval of multiple streams of data from the work environment'. The system includes overview snapshots of the workspace, screenshots of in-space computers, whiteboard images, and digital photos of physical objects. The importance of this work stems from its identification of critical considerations of knowledge capture tools for design workspaces, which differ from those that are more of a structured meeting or a classroom environment.

\subsection{Helaba system}

In another study, Gutierrez Lopez et al. (2018) described the essential characteristics needed for facilitating the traceability of creative design processes. They constructed a prototype for recording and revisiting the evolution of design artefacts. This prototype was used to connect artefacts, design rationale, and decisions in a shared workspace.

In addition to being based on collected periodic feedback, this prototype employed Helaba, a system for highlighting design rationale in collaborative design processes, to collect the artefacts, communications, and decisions produced by teams during the design process. The prototype was used to evaluate 'how design rationale and traceability can be used in UCD processes'.

Helaba, which is an extension of a previous study (Gutierrez Lopez et al., 2015), was used for creating extensive pictures of the design process for each of the teams, allowing them to further investigate the traceability: teams could track their design processes using a lean, structured repository and a shared common workspace for the annotation of artefacts. Their UCD project findings suggest that tracking progress in different phases of processes can be assisted by having a lean repository of artefacts annotated with design rationale. The outcome partially involves the consolidation of the aim of Protobooth Oulu, which automates the documentation of design prototypes to ensure the consistency and tracking of evolving artefacts, to support feedback, and assist in future planning for design steps. Table 1 shows a comparison between the WorkspaceNavigator, Helaba, and Protobooth Oulu systems.

Table 1. Comparison between WorkspaceNavigator, Helaba, and Protobooth Oulu

\begin{tabular}{|c|c|c|c|}
\hline System & Addressed Problem & $\begin{array}{c}\text { Target } \\
\text { Environment }\end{array}$ & Technology \\
\hline $\begin{array}{l}\text { Workspace } \\
\text {-Navigator }\end{array}$ & $\begin{array}{l}\text { Documentation during } \\
\text { prototyping phases }\end{array}$ & Meeting & $\begin{array}{l}\text { Snapshots of the workspace; Screenshots } \\
\text { of in-space computers; Whiteboard images; } \\
\text { Digital photos of physical objects }\end{array}$ \\
\hline Helaba & $\begin{array}{l}\text { Design rationale and } \\
\text { traceability in UCD } \\
\text { processes }\end{array}$ & $\begin{array}{l}\text { Collaborative } \\
\text { workspace }\end{array}$ & $\begin{array}{l}\text { Extensive pictures of the design process; } \\
\text { Feedback; Shared common workspace for } \\
\text { annotation of artefacts }\end{array}$ \\
\hline $\begin{array}{l}\text { Protobooth } \\
\text { Oulu }\end{array}$ & $\begin{array}{l}\text { Design activity in } \\
\text { prototyping and } \\
\text { facilitating its } \\
\text { documentation }\end{array}$ & $\begin{array}{l}\text { Educational } \\
\text { classroom }\end{array}$ & $\begin{array}{l}\text { Automated timely mannered pictures of } \\
\text { prototype from different angles/views; } \\
\text { Feedback and interaction through social } \\
\text { media }\end{array}$ \\
\hline
\end{tabular}

\section{GOALS AND METHODOLOGY}

\subsection{Goals}

In this paper, we describe the fabrication and preliminary testing of Protobooth Oulu, a system that can be used to document the process for prototyping products by capturing process-output 'snapshots' in time during the early stages of product development (PD). Our hypothesis is that our new system will help facilitate the documentation of the design process and prototyping of artefacts in educational settings (e.g. during courses) for students and instructors alike. The system is able to capture outputs from activities (i.e. prototypes) but not the activities themselves [e.g. when using video coding (Edelman and Leifer, 2012)]. We believe that early stages are more interesting from the viewpoint of 
creativity, as creativity is in focus then (before defining requirements), whereas meeting specifications is probably more in focus later. Furthermore, in order to use such a system for capturing prototyping in design in a manufacturing context, additional functionality should be targeted, for example, a robust and informative database of the captures.

Protobooth Oulu, which is based on a system developed by the Norwegian University of Science and Technology (NTNU) in Norway (Sjöman et al., 2017), explicitly targets documentation in educational environments. It facilitates the documentation process, making it more reflective. Feedback and interactions (between students and between students and instructors) utilize social media to positively influence the learning environment and outcomes. We hope to make designers reflect on their concepts (by reviewing their prototypes). A further and overarching goal is not only to produce documentation that can be used by practitioners and designers, but can also be used in research.

\subsection{Protobooth}

The Protobooth system presented by Sjöman et al. (2017) helps the researcher obtain more data on projects. It is used for capturing physical prototypes from ongoing early-stage product development projects with the aim of giving researchers access to 'information and knowledge from early-stage PD'. The system is composed of a 'digital repository for collecting, storing and sharing data from design output (prototypes), and a physical instrument for capturing the input data'. Its digital repository currently consists of data from various prototyping projects. The physical instrument presented in Sjöman et al. (2017) has two cameras that are used for capturing multiview images of prototypes and metadata (i.e. information on who, when, and where the prototype was captured, essentially linking pictures with users through the use of radio frequency identification cards ( RFID)). A key point in Protobooth is that prototypes are captured because they are output from the design activity, thus targeting (ultimately) research the activity. The link between the activity and the artefact is a core concept (and assumption) of that paper.

In a later system presented by Kohtala et al. (2018), better cameras and a turntable were added for experimenting with 3D scanning and generating 3D models. Additionally, that system had a microcontroller logger and could also produce laser-cut pieces from sketches in order to identify causalities in the early stages of PD. Kohtala et al. (2018) discussed various ways of representing a prototype repository, including possible accessibility through virtual reality. The system produces a basis for documentation and feedback, helps in exploring potentially supportive methods (i.e. photogrammetry) in the early stages of $\mathrm{PD}$, and highlights the limitations of capturing design output from projects.

\subsection{Why Protobooth Oulu?}

Protobooth Oulu is a system that aims to achieve effortless documentation by capturing prototypes of developing products in their early stages during educational courses. 'Effortless' means that we want the system to require minimum effort when it is used: the system needs to be activated as the student follows simple steps. In addition to saving time, Protobooth Oulu makes the documentation process integrative to the classroom. Additionally, documentation can easily be accessible by the students, and later their instructors. Table 2 presents and discusses Protobooth Oulu with regard to its observations and limits.

\subsection{Case study: Principles of Digital Fabrication course}

The Protobooth Oulu system was tested during the Principles of Digital Fabrication course in 2018 at the University of Oulu, where 10 teams (out of 25 active teams in the course) documented their coursework over six weeks (weeks 4 to 9 of the course). Protobooth Oulu was used to facilitate the students' documentation and provide the instructors with a timely indication of the prototyping progress.

The course requires students to build an interactive robot that combines mechanical, electrical, and software components using the tools and devices that exist at FabLab Oulu. The course follows a project-based learning approach combined with several practical tutorials where students acquire basic principles and guidelines for digital fabrication. Students learn how to design mechanical components with solid modelling tools, how to use these parts with sensors and actuators to create a physical gadget (robot), and how to program the robot so it can interact with the world around it. Students work in small teams, grouped at the beginning of the course, and meet weekly with a course tutor to obtain constructive feedback. Students were introduced to Protobooth Oulu on a certain date (April 10). They 
were told that it is essential for them to have at least one capture of their prototype each week. When capturing a prototype by activating the system with an RFID card, the system also captures what RFID card was used, linking the user to the prototype that was captured. To simplify the process, each team was instructed to use an RFID card already in their possession (such as a bus card or student card) to trigger the capture. Teams were asked to use the same RFID card throughout the course.

Table 2. Capabilities of Protobooth Oulu and its limits

\begin{tabular}{|c|c|c|}
\hline Advantage & Explanation & Limitation \\
\hline $\begin{array}{l}\text { Ease of use } \\
\text { and setup }\end{array}$ & $\begin{array}{l}\text { Plug in the system to power and it is ready to } \\
\text { use; students simply tab their ID card to } \\
\text { produce documentation }\end{array}$ & $\begin{array}{l}\text { For now, design rationale is added } \\
\text { after the capture }\end{array}$ \\
\hline $\begin{array}{l}\text { Easy to } \\
\text { manufacture }\end{array}$ & $\begin{array}{l}\text { Material used and fabrication process is not } \\
\text { demanding }\end{array}$ & Not durable; MDF w \\
\hline Portability & It is a box that you can carry around & \\
\hline User friendly & $\begin{array}{l}\text { Uses a blog online; documentation is presented } \\
\text { in a timeline manner }\end{array}$ & $\begin{array}{l}\text { Currently, only pictures of } \\
\text { artefacts were taken and posted }\end{array}$ \\
\hline $\begin{array}{l}\text { Socially } \\
\text { interactive }\end{array}$ & $\begin{array}{l}\text { Blog space can be used to view, modify, and } \\
\text { add to the documentation }\end{array}$ & $\begin{array}{l}\text { Students do need to use login } \\
\text { credentials to modify or add to } \\
\text { their documentation }\end{array}$ \\
\hline Motivational & $\begin{array}{l}\text { Peers can share their documentation on social } \\
\text { media, communicate and stay up to date with } \\
\text { their peers through social media }\end{array}$ & $\begin{array}{l}\text { Extra work is needed to add new } \\
\text { functionalities }\end{array}$ \\
\hline
\end{tabular}

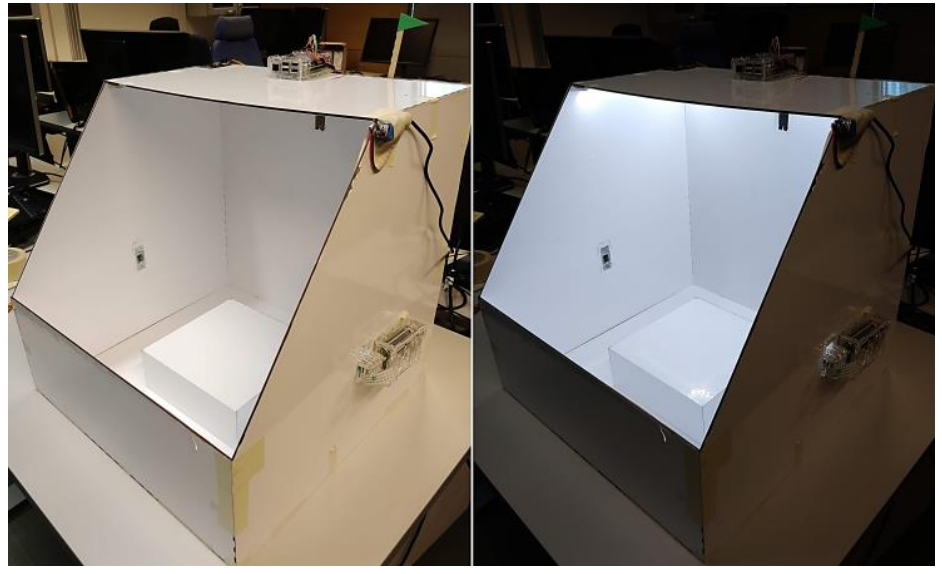

Figure 2. Protobooth Oulu. System is shown when lights are off/on. System was placed beside main door of FabLab Oulu.

\subsection{System functionality}

The Protobooth has three cameras, located so that each captures different views/angles of the prototype. Each time a prototype is captured, a new WordPress (WP) blog post is created, and the captured image is imported to the media library and attached to that post. The blog format was used to provide easy access for students. WP was chosen in particular because of its convenience (number of features and availability). This differs from creating a repository/database and accessing that data through a graphical interface in terms of easy access from various devices and the further possibility of editing the data from various devices. In order for the data to be used for research, it is advantageous to store them in a fashion in addition to the WP format, for instance, a dedicated repository/database. In our test system, we do not store the data elsewhere. To capture prototypes, students place their prototypes inside the Protobooth and expose their team RFID card to the RFID reader, which initiates the image capturing process. A servo-controlled flag waves, indicating that the capturing process is in progress. From this point onward, the system takes care of the remaining steps automatically. Each blog post is given a title composed of a time stamp of its capture date and time, camera number, and an RFID unique card ID (UID). 
Table 3. Number of captures for each team over period of course

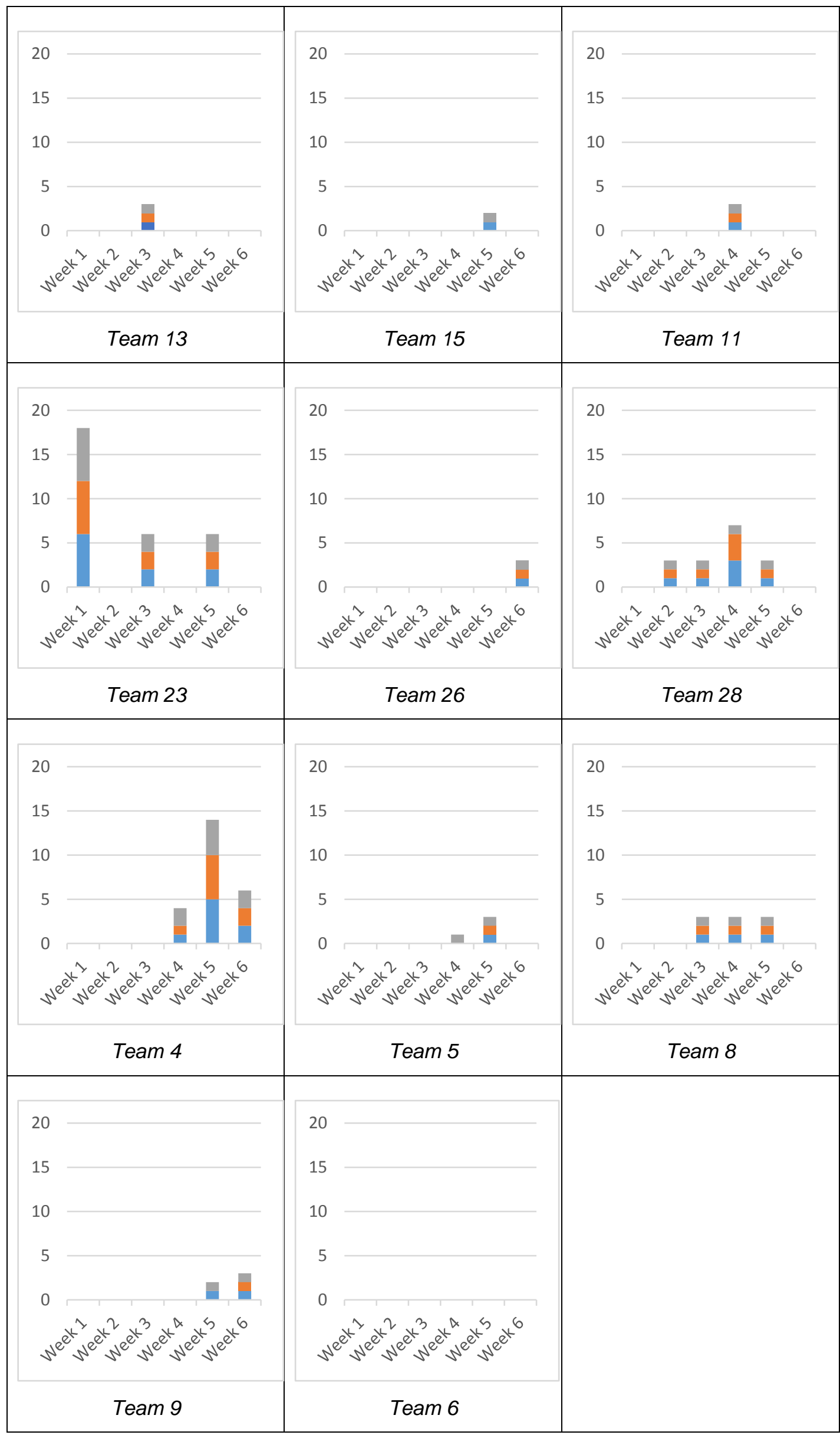


Table 4. Example captures of four teams. Pictures taken during different stages. First column: early stages (first three weeks), 2nd column: during week four, and 3rd column: artefacts at final stages (weeks five and six). Each row shows a different team.

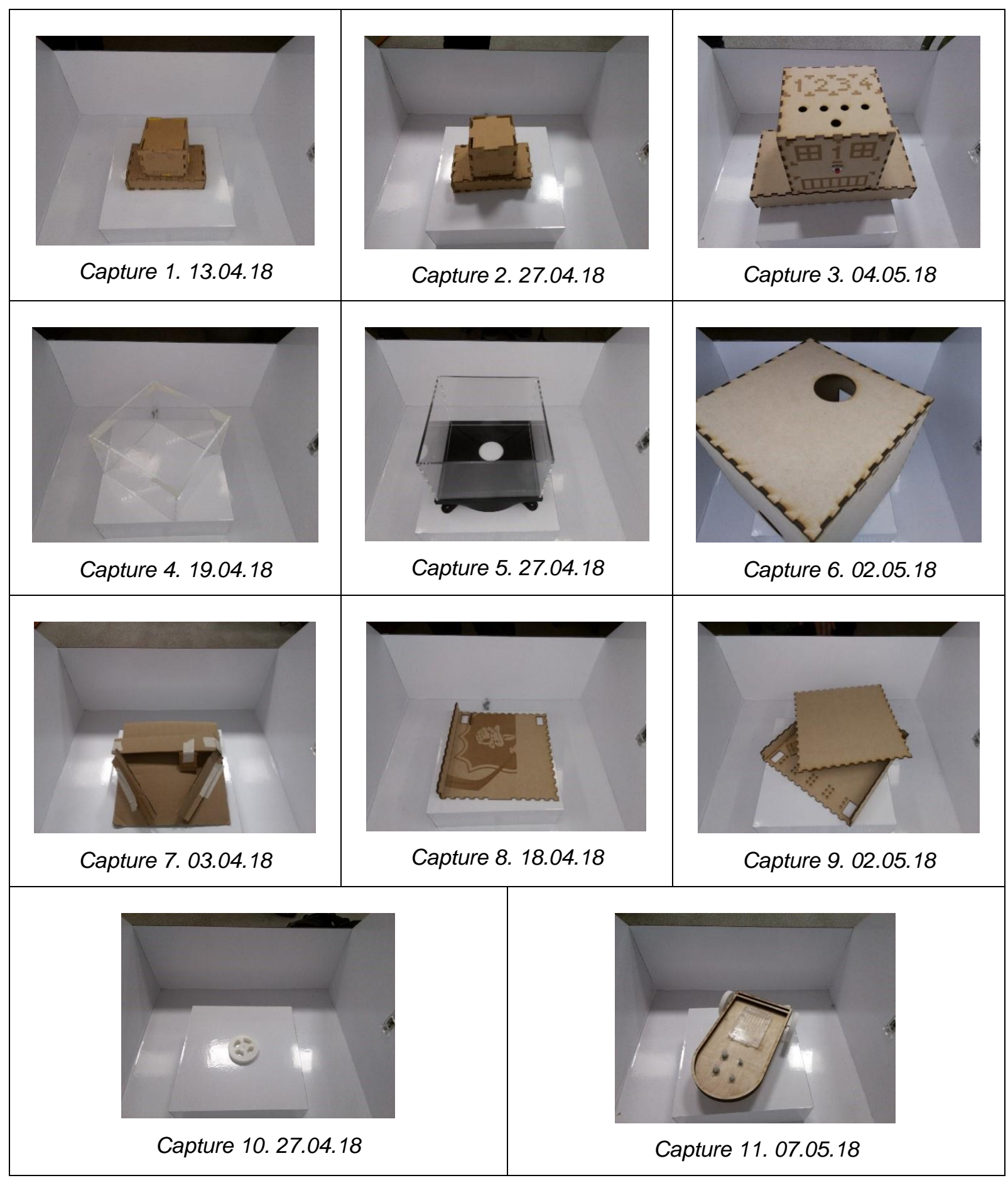

\subsection{System implementation}

The system has multiple parts. The outer container of Protobooth is a laser-cut finger-joint box (medium-density fibreboard material). The interior is covered with sheets of even-white thin selfadhesive plastic (vinyl). For capturing images, the system includes three Raspberry Pi 3 model Bs in addition to three cameras (Raspberry Pi camera modules) and a power adapter for each Raspberry Pi. To activate the system and track students' IDs, we used an RC522 RFID module. For even lighting, an LED strip was placed inside the box. All three Raspberry Pis were connected through WiFi to a local network. One of them was used to build a Linux, Apache, MySQL, and PHP (LAMP) web server with WP hosted on it. All nonvisual aspects of the prototype (e.g. the LAMP server setup and code for 
running the system) are documented step-by-step online (University of Oulu Wiki; https://wiki.oulu.fi/display/ ybarhous/Proto-booth [private]).

\section{RESULTS}

The results of the case study of a nine-week project-based bachelor course at FabLab Oulu included the captures of 10 student teams that spanned week 4 to week 9 of the course. Table 3 lists the number of captures for each team over the period of the course. Different cameras are shown in different colours. The columns show captures from the three cameras of the system, with one or more captures per week (e.g. team 13 had one capture per camera in the third week, while team 23 had six captures per camera, for a total of 18 in the first week). Team 6 did not have any captures because they did all their capturing after the deadline. Table 4 lists example captures from the four teams, where pictures were taken during different stages. The evolution and major changes in the prototypes can be observed when looking at the results from a qualitative point of view.

A quantitative analysis [chi-square test for independence and Cramér's phi (coefficient)] showed no significant correlation between the number of captures and the completion in time or course grades, possibly owing to the limited number of cases. However, inspection of the data shows certain patterns from reviewing the captured data. We consider these patterns of captures and stages of the prototypes as important to study in more detail in future iterations of the system. We made the following subjective observations when reviewing the captured data: (1) Peaks of number of captures toward the end of the period; (2) Diverse patterns in capture in time; and (3) A wide range of stages of the prototypes.

\section{DIscussion}

The current system is specifically designed to be placed in educational environments. Its aim is to achieve an effortless way to document the prototyping process of developing products during courses by facilitating students' documentation and providing instructors with temporal data on output from the prototyping progress. Although the idea of documenting a prototyping process primarily by images does not seem too useful at this point (the current system is restricted to capturing images, uploading them to a locally hosted WP blog, and displaying them as blog posts, ordered according to their capture time), future systems should include the design rationale at the time of capture (Bracewell et al., 2009). Examples of such nonvisual aspects of prototype documentation are the purpose, successfulness or the prototype or degree of learning utility.

When students were asked about their experience with the system, they appreciated the idea of not taking pictures (e.g. using smartphones) and having to upload them online themselves. They also favoured the idea of automating the blog posting process (not having to follow the standard process of signing in online, creating a new post, attaching an image to it, and sharing that post). Additionally, instructors liked the fact that they only needed to scroll through a blog for updates about the students' progress.

Overall, when evaluating the current system, we observed that it was not as efficient as intended. One indicator of this is that, occasionally, there were interrupted captures (e.g. in Table 3, team 5 in week 4), probably owing to captures taking more time than expected or interruptions in the wireless network connection. Hence, the system can be improved in terms of the speed of capture and connectivity.

The observed peaks of the number of captures toward the end of the period (see Table 3 ) is probably a norm for all projects with a deadline, specifically in the education field. This is highlighted by the fact that team 6 made its only capture after the deadline. On the other hand, since students (and professionals) tend to work harder immediately before deadlines, one can argue that prototyping cycles are slower toward the end of a project, as prototypes are often more complex at this stage.

We managed to capture prototypes over time. These data be used to understand the process of prototyping and consequently provide a means to improve performance. We consider that the system changes how the students interact with their (physical) prototypes. For example, possibly more such interactions were observed in the case of team 23 (see Table 4), who were able to revise and simplify their ideas for the prototypes. They had several realizations based on the early prototypes (in the first week) of the four-tile Mahjong shuffler they were building.

As this was a test system and not many teams used it (Tables 3 and 4), we did not generate documentation or evaluate if our efforts were successful. This will be the focus in the next iteration of the system.

The test system helps to choose what to do next. A consideration is to find a way to capture what questions motivate each prototype (e.g. 'generative design questions' or 'deep reasoning questions') 
(Gerstenberg et al., 2015). This could be implemented through simple inputs (e.g. buttons) on the Protobooth Oulu system that can be pressed while capturing. Users do not annotate the blog posts after the prototypes are captured, and this is a feature to implement in the next iteration of the system. We did not measure if the students interacted with the prototypes after they were captured. This can be measured with another documentation system that we are currently developing for design education in the context of digital fabrication (Sánchez Milara et al., 2019).

\section{CONCLUSION AND PERSPECTIVES}

In this paper, we described the fabrication and preliminary testing of Protobooth Oulu, a system that aims to achieve an effortless and efficient method of documentation. Protobooth Oulu can be used for documenting the process of prototyping products through capturing process output 'snapshots' in time at the early stages of PD. These early stages are more interesting from the viewpoint of creativity, as creativity is in focus (before defining requirements), whereas meeting specifications is perhaps more in focus later. The system can capture output from activity (i.e. prototypes) but not the activity itself (e.g. when using video coding). The system requires several simple and straightforward steps, followed by students, to create documentation easily accessible by these students, and later their instructors.

The developed system is based on Protobooth developed by NTNU, Norway (Sjöman et al., 2017), but it explicitly targets documentation in educational environments. The primary goal of such a system is to make designers reflect on their concepts (by reviewing their prototypes). A further and overarching goal is not only to produce documentation that can be used by practitioners and designers, but can also be used in research. As a case study, Protobooth was used during a nine-week project-based bachelor course at FabLab Oulu. The qualitative results showed evolution and major changes in the prototypes. A quantitative analysis showed no significant relationship between the number of captures and completion in time or course grades, possibly owing to the limited number of cases. However, specific patterns appeared when reviewing the captured data. To support future planning for design steps, an effortless and reliable Protobooth system is a needed asset. Using Protobooth Oulu, we captured prototypes over time. These data can be used for understanding the process of prototyping and consequently provide a means to improve performance. We consider that the system changes how the students interact with their (physical) prototypes.

Overall, when evaluating the current system, we observed that it was not as efficient as intended. An indicator of this is occasionally interrupted captures. This was probably owing to captures taking more time than expected or interruptions in the wireless network connection. Hence, the system can be improved in terms of speed of capture and connectivity.

For future versions of the system, extra functionalities can be added. To improve the system's inputs, additional input data can be obtained by implementing sensors that can reveal more about the material used or under which conditions the capturing was done (readings from the surrounding environment). For example, (Kohtala et al. 2018) experimented with measuring the weight of the prototype through load cells in their version of Protobooth. They believed that it might be possible to detect materials with object recognition reinforced by weight, e.g. to distinguish cardboard from MDF.

Another functionality that can be added to the system is a hyperspectral imaging system (Chang, 2007). Hyperspectral imaging collects and processes information from across the electromagnetic spectrum. It provides a very high-resolution array of pixels at different wavelengths. The goal of hyperspectral imaging is to obtain the spectrum for each pixel in the image of a scene, with the purpose of finding objects, identifying materials, or detecting processes (Chang, 2003; Grahn and Geladi, 2007).

With regard to the output interface, we plan on continuing with WP: it is easy to use, scalable, and does not require much coding. Currently, most of the capturing and posting is written in Bash using WP-CLI (the command-line interface for WordPress). WP-CLI can update plugins, configure multisite installs, and much more, without using a web browser. Additionally, WP is distinguished by its customizability and great flexibility: blog posts can be displayed in a timeline manner using a variety of themes, making it easier to visualize the content. WP plugins can also be used to conduct real-time analytics for posts or media. WP tags can also be employed for better filtering options. Moreover, WP open-source content management features can be further utilized: although one can edit any post at any time, the current system has only one user with such credentials (WP administrator). An improved system would have a user database (a user ID for each UID), making it possible for teams to log in and 
edit their posts, add detailed descriptions, or comment on the images. This would fuel interactions between the students and the students and instructors, allowing for feedback exchange. Further functionality can utilize other social media platforms for the image sharing of prototypes (i.e. Instagram) to influence the learning environment and outcomes positively. Posting to Instagram (or any other social network) can help promote students' achievements, allow for recognition, and provide better feedback.

\section{REFERENCES}

Bracewell, R., Wallace, K., Moss, M. and Knott, D. (2009), "Capturing design rationale”. Computer-Aided Design, Vol. 41 No. 3, pp.173-186.

Chang, C.-I. (2003), "Hyperspectral Imaging: Techniques for Spectral Detection and Classification”, Springer Science \& Business Media.

Chang, C.-I. (2007), "Hyperspectral Data Exploitation: Theory and Applications”, John Wiley \& Sons.

Dalsgaard, P. and Halskov, K. (2012), "Reflective Design Documentation”, Proceedings of the Designing Interactive Systems Conference, ACM, New York, NY, USA, pp. 428-437.

Dorst, K. and Cross, N. (2001), "Creativity in the design process: co-evolution of problem-solution", Design Studies, Vol. 22 No. 5, pp. 425-437.

Edelman, J.A. and Leifer, L. (2012), "Qualitative Methods and Metrics for Assessing Wayfinding and Navigation in Engineering Design", in Plattner, H., Meinel, C. and Leifer, L. (Eds.), Design Thinking Research: Measuring Performance in Context, Springer, Berlin, Heidelberg, pp. 151-181.

Gerstenberg, A., Sjöman, H., Reime, T., Abrahamsson, P. and Steinert, M. (2015), "A Simultaneous, Multidisciplinary Development and Design Journey - Reflections on Prototyping”, in Chorianopoulos, K., Divitini, M., Baalsrud Hauge, J., Jaccheri, L. and Malaka, R. (Eds.), Entertainment Computing - ICEC 2015, Springer International Publishing, pp. 409-416.

Grahn, H. and Geladi, P. (2007), “Techniques and Applications of Hyperspectral Image Analysis”, John Wiley \& Sons.

Gutierrez Lopez, M., Haesen, M., Luyten, K. and Coninx, K. (2015), "Helaba: A System to Highlight Design Rationale in Collaborative Design Processes", in Luo, Y. (Ed.), Cooperative Design, Visualization, and Engineering, Springer International Publishing, pp. 175-184.

Gutierrez Lopez, M., Rovelo Ruiz, G., Luyten, K., Haesen, M. and Coninx, K. (2018), "Re-thinking Traceability: A Prototype to Record and Revisit the Evolution of Design Artefacts", Proceedings of the 2018 ACM Conference on Supporting Groupwork, ACM, New York, NY, USA, pp. 196-208.

Herstatt, C., Stockstrom, C., Verworn, B. and Nagahira, A. (2006), “'Fuzzy front end' practices in innovating japanese companies", International Journal of Innovation and Technology Management, Vol. 03 No. 01, pp. 43-60.

Ju, W., Ionescu, A., Neeley, L. and Winograd, T. (2004), "Where the Wild Things Work: Capturing Shared Physical Design Workspaces", Proceedings of the 2004 ACM Conference on Computer Supported Cooperative Work, ACM, New York, NY, USA, pp. 533-541.

Kohtala, S.M.I., Erichsen, J.A.B., Sjöman, H., Steinert, M. (2018), “Augmenting Physical Prototype Activities in Early-Stage Product Development”. DS 91: Proceedings of NordDesign 2018, Linköping, Sweden, 14th 17th August 2018 Design in the Era of Digitalization. https://doi.org/10.1109/ice.2017.8279935

Leifer, L.J. and Steinert, M. (2011), "Dancing with ambiguity: Causality behavior, design thinking, and tripleloop-learning”, Information Knowledge Systems Management, Vol. 10 No. 1-4, pp. 151-173.

Perry, M. and Sanderson, D. (1998), "Coordinating joint design work: the role of communication and artefacts", Design Studies, Vol. 19 No. 3, pp. 273-288.

Pierce, J., Sengers, P., Hirsch, T., Jenkins, T., Gaver, W. and DiSalvo, C. (2015), "Expanding and Refining Design and Criticality in HCI", Proceedings of the 33rd Annual ACM Conference on Human Factors in Computing Systems, ACM, New York, NY, USA, pp. 2083-2092.

Sjöman, H., Erichsen, J.A.B., Welo, T. and Steinert, M. (2017), "Effortless capture of design output a prerequisite for building a design repository with quantified design output", 2017 International Conference on Engineering, Technology and Innovation (ICE/ITMC), presented at the 2017 International Conference on Engineering, Technology and Innovation (ICE/ITMC), pp. 564-570.

Swan, L., Tanase, D. and Taylor, A.S. (2010), "Design's Processional Character", Proceedings of the 8th ACM Conference on Designing Interactive Systems, ACM, New York, NY, USA, pp. 65-74.

Wolf, T.V., Rode, J.A., Sussman, J. and Kellogg, W.A. (2006), “Dispelling 'Design' As the Black Art of CHI”, Proceedings of the SIGCHI Conference on Human Factors in Computing Systems, ACM, New York, NY, USA, pp. 521-530.

Zimmerman, J., Stolterman, E. and Forlizzi, J. (2010), “An Analysis and Critique of Research Through Design: Towards a Formalization of a Research Approach", Proceedings of the 8th ACM Conference on Designing Interactive Systems, ACM, New York, NY, USA, pp. 310-319. 